\title{
Enhancing Capstone Design with an Industry Sponsored Project Center
}

\author{
Shih-Liang (Sid) Wang \\ Department of Mechanical and Chemical Engineering \\ North Carolina A\&T State University \\ Greensboro, NC 27411, USA
}

\section{Mechanical Engineering Capstone Design}

Senior capstone design courses have become a critical component of undergraduate engineering education, as mandated by the Accreditation Board for Engineering and Technology (ABET). The Mechanical Engineering Senior Capstone Design at North Carolina A\&T State University (NC A\&T) is a two-semester project course. The course allows students to take design projects from conceptual design to prototype fabrication, testing and evaluation. Projects are ranging from industry sponsored projects and design competitions sponsored by professional societies. The competitions include Society of Automotive Engineers (SAE) Aero Design Competition, Formula SAE, and Mini Baja, and American Society of Mechanical Engineers (ASME) Design Competition. Industry sponsored projects include those from Gillette, Boeing, Caterpillar, Kimberly Clark, Michelin, and others.

Industry sponsored projects allow students to work on actual, meaningful engineering design projects that relate theory with practical applications. Sponsoring companies provide opportunities for students to gain experience with realistic applications along with funding to support the project. Unfortunately, NC A\&T is not adjacent to major industrial regions, and the distance between the University and sponsoring companies tend to limit effective implementation of projects. Scheduling plant tours for students to view background information is difficult or impossible, and similar difficulties exist in building relationships with liaison engineers. An effective liaison engineer must dedicate a fair amount of time to address student questions, review designs, and help find supporting data and information. In the current climate of corporate lean operation, few engineers are in a position to volunteer their time in this capacity.

Another barrier to industry sponsored projects is a lack of strong mentoring by faculty members who are experienced in the subject area. Each capstone design course at NC A\&T is coordinated by a faculty member, with remaining faculty members assigned as advisors to individual project sections on a rotating basis. Unfortunately, rotating faculty advisors does not help build expertise specific to subject areas, as most faculty have little or no industrial experience. 
The limitations of faculty mentoring and the significant challenges of industry support leave the capstone design course with significant opportunities for improvement. Strong, focused, and comprehensive industry support with a long-term commitment is needed.

\section{The Gillette Project Center}

In 2003, The Gillette Company made a long-term commitment to NC A\&T, funding student scholarships with internships, faculty fellowships, and establishing a Project Center. The Gillette Project Center was created to provide students with an opportunity to gain project related experience for the design of Gillette products and manufacturing equipment. The Gillette Faculty Fellowship, similar to the Boeing Faculty Fellowship [1], encourages faculty to be more engaged in engineering practice by allowing professors to spend an extended period of time at Gillette to learn of their business and technological requirements. The fellowship enables faculty to gain indepth knowledge from Gillette personnel, which helps alleviate the workload of Gillette liaison. The fellowship also provides an opportunity for the faculty advisor to identify suitable project activities, ensuring a good match of project scopes to student capabilities.

\section{Design Projects}

The first year (2003-4) project is building a cam test stand for the learning and testing of mechanical cams. Two cams and associated linkages, as shown in Figure 1, were removed from Gillette surplus machines and donated to NC A\&T. Since the cams, followers, and slides are already assembled, a significant amount of effort in machining and purchasing are saved. The cam test stand, as shown in Figure 2, has two cams: one double-dwell cam and one four-dwell cam. The double-dwell cam controls a slide in the vertical direction and the four-dwell cam controls the slide in the horizontal direction.

The cam test stand is powered by a DC motor with a speed controller. Motion sensors to measure position, velocity, and acceleration are incorporated. Linear motion sensors are placed at the end of the slide, and angular motion sensors are placed along the cam shaft, as shown in Figure 3. A force sensor is used to measure the contact force by the slide. The stand is mounted on a cart with retractable caster wheels, as shown in Figure 4. The cart becomes a firm stand with the studs extended, and it is transformed to a mobile cart with studs retracted. The front panel of the stand has a speed control dial and receptacles to get readouts from different sensors to an oscilloscope. The cam test stand remains at the NC A\&T campus after the end of this project, and will be utilized as a lab module to demonstrate cams, motion control, and sensors.

In the second year, the project is to design a device to test the functionality of the Gillette M3 Power Shave button, as shown in Figure 5. The apparatus is to test the button on the handle before the assembly of the cartridge and handle. The testing device is designed to press the button to check if the shave is on, and then press the button to check if it is off. Inoperative handles should be removed to an ejection bin. Figure 6 shows the prototype test stand, and Figure 7 show the side view of the test stand. A cam is used to turn on and off the razor, and a microphone is used to pickup the buzz and determine if the raze is on or not. Figure 8 shows the front view of the cam. 


\section{Course Modules for Capstone Design}

Many students experience difficulties in a project-based design course because most students lack hands-on experience with electrical and mechanical systems. Unlike students from past generations, engineering students today typically have little or no experience repairing cars, appliances, or toys. Additionally, students are lack shop skills since this requirement has been removed from many engineering curricula.

Course modules for capstone design are developed to augment information available from textbooks and other sources. Many textbooks cover project management and design processes, but unfortunately not all application specific data is readily available. Although numerous catalogues and design guidelines $[2,3,4]$ are available on-line, it is difficult for students to identify and retrieve all relevant information. The course modules fill the information gap relative to critical mechanical and electrical components and systems.

For example, to help visualize the cam in motion, like the one shown in Figure 1, computer simulation using Working Model 2D [5] was developed, as shown in Figure 9. This type of learning modules is necessary as kinematics is an elective course in the Mechanical Engineering curriculum at NC A\&T, and not all students have exposures of cams and linkages. Courseware on motors and sensors are also developed.

\section{Discussion}

North Carolina A\&T State University is one of the nation's leading institutions of higher learning, graduating more African American engineers and technologists than any other university in the country. The Gillette Company, headquartered in Boston, MA, is the world leader of grooming products - blades, razors and shaving preparations. The Gillette/ NC A\&T partnership is beneficial to both the university and Gillette. Gillette will identify and recruit the best and brightest minority graduates, and NC A\&T will gain additional resources to enhance the capstone design course to better prepare their students for industry.

The project center has demonstrated the long-term commitment by Gillette. However, challenges remain, and chief among them is to identify suitable project topics that are relevant to Gillette and can fit in university's timeline, equipment, and skill sets of students, technicians, and faculty. As the institution knowledge and skill sets develop with the advancement of this partnership, the operation of the Center should become smooth.

\section{Acknowledgements}

Mr. Edwin Ryan, Vice President for Gillette Engineering Implementation Group in Grooming Products, is the champion behind this Project Center. He provided the leadership and resources to make the Center a reality. The author also wants to thank Mr. Royall Mack, Vice President for Gillette Civil Affair, who spearheaded the Gillette/ NC A\&T Partnership. Mr. Paul Burt, Manager of the Electrical Controls Systems at Gillette, coordinates all aspects of this Project Center at Gillette, and is the first year Liaison engineer. His dedication and perseverance is much appreciated. 


\section{Reference:}

1. Boeing - A. D. Welliver Faculty Summer Fellowship http://www.boeing.com/companyoffices/pwu/fellowship/objective.html

2. Machine Design magazine http://www.machinedesign.com

3. Thomas Register http://www.thomasregister.com

4. Design News magazine http://www.manufacturing.net/dn/index.asp

5. MSC.Software, URL: http://www.workingModel.com/.

\section{Biographical Information}

Shih-Liang (Sid) Wang is Professor and Interim Chair of Department Mechanical and Chemical Engineering at North Carolina A\&T State University. Dr. Wang received his Ph.D. in mechanical engineering at Ohio State University in 1986. His research interests include computer-aided design, machine and mechanism design, motion simulation of mechanical systems, design theory and methodology, and robotics.

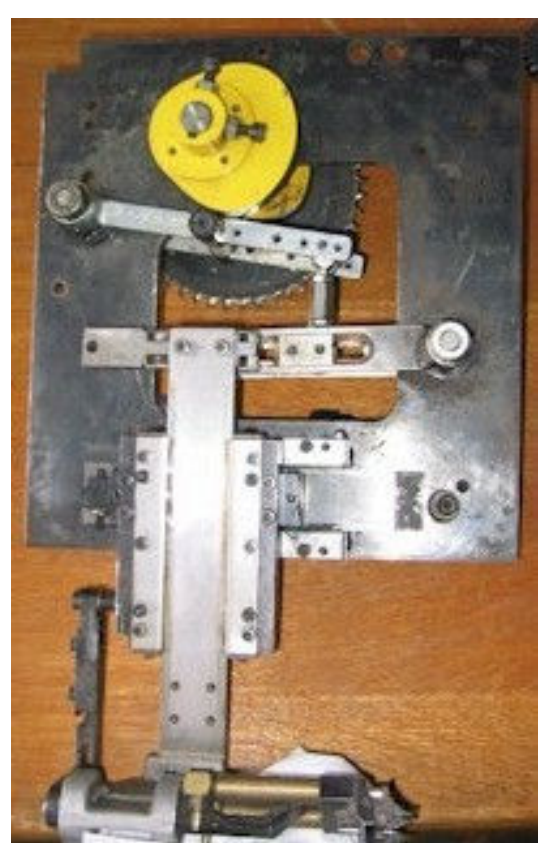

Figure 1 Cam Tooling from Gillette

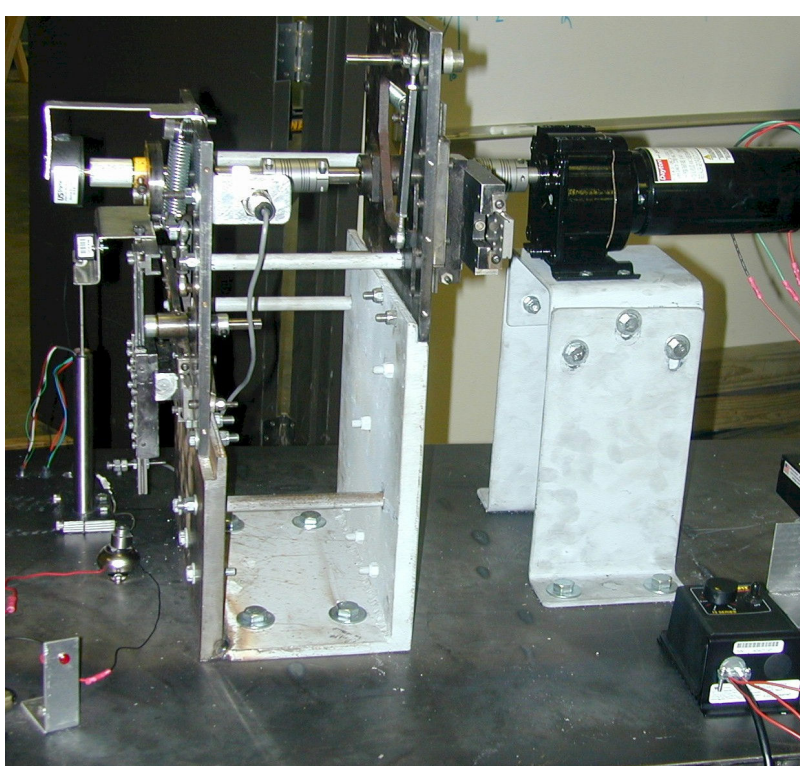

Figure 2 Cam Test Stand 


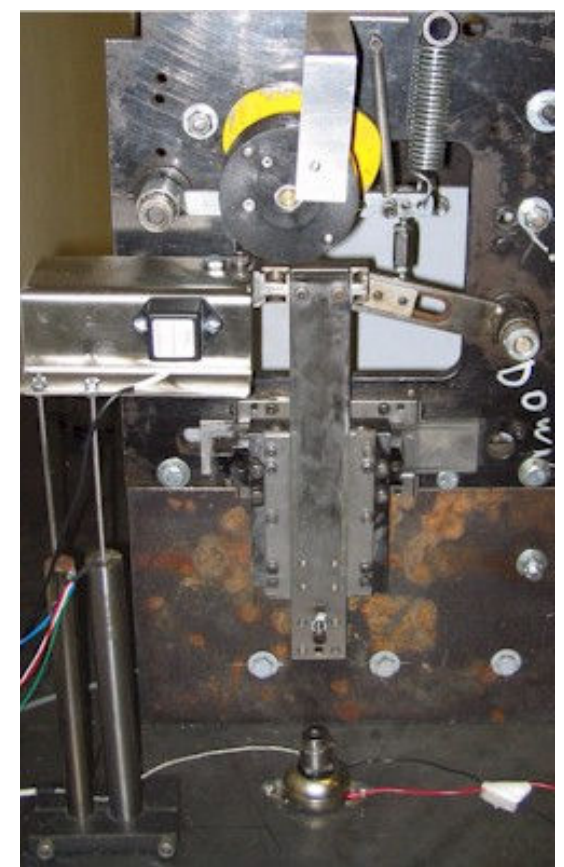

Figure 3 Cams with Sensors

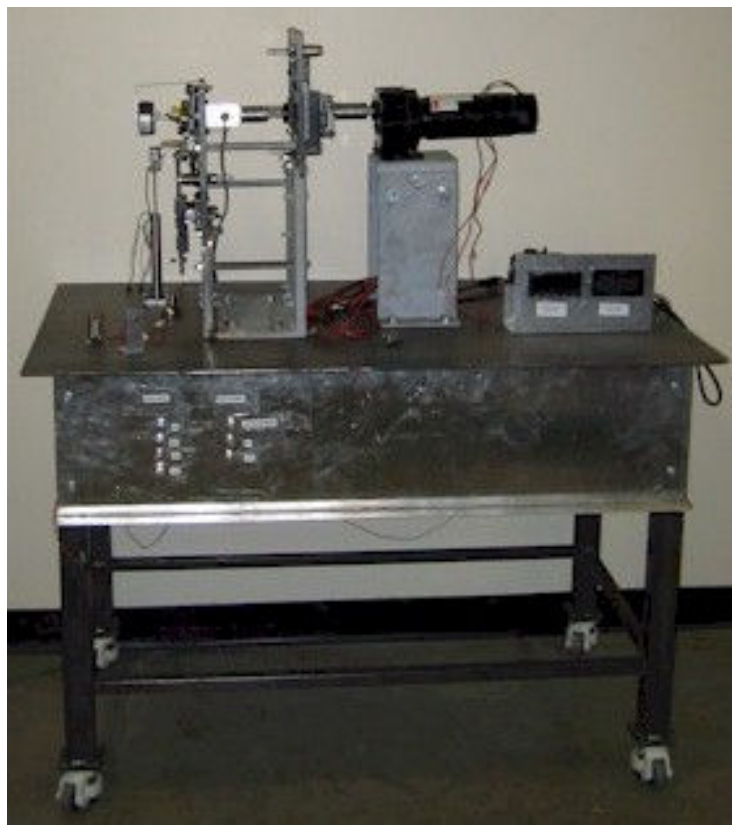

Figure 4 Cam Test Stand on the Cart

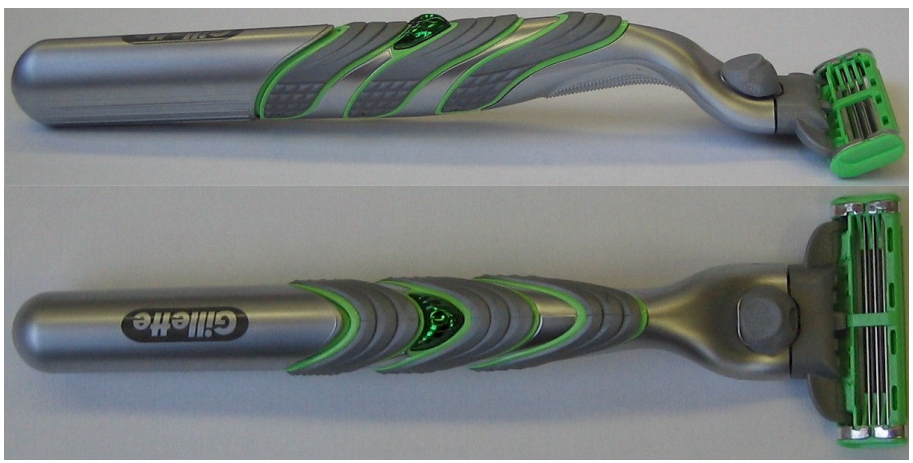

Figure 5 Gillette M3 Power Shave

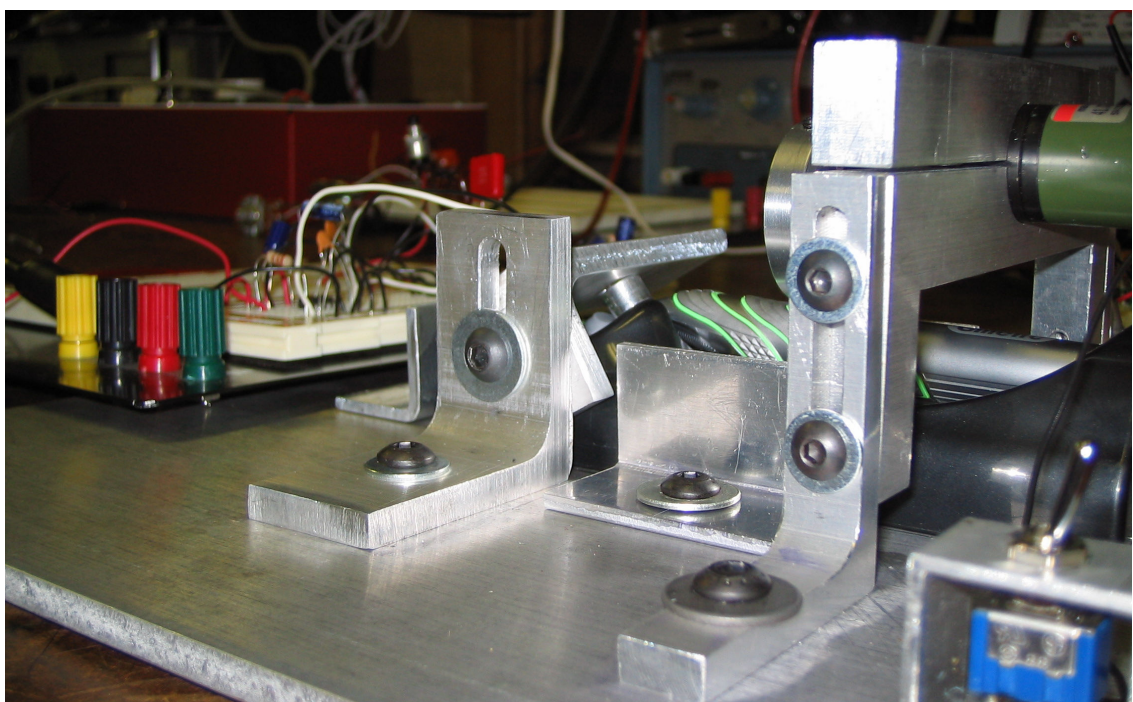

Figure 6 Gillette M3 Power Shave Test Stand

Proceedings of the 2005 American Society for Engineering Education Annual Conference \& Exposition Copyright (C) 2005, American Society for Engineering Education" 


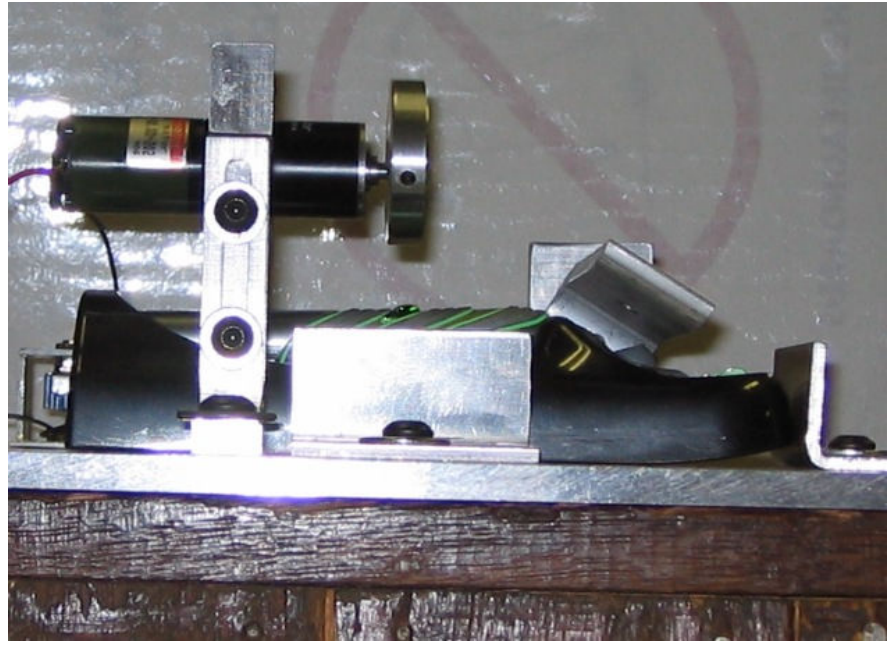

Figure 7 Side View of the Test Stand

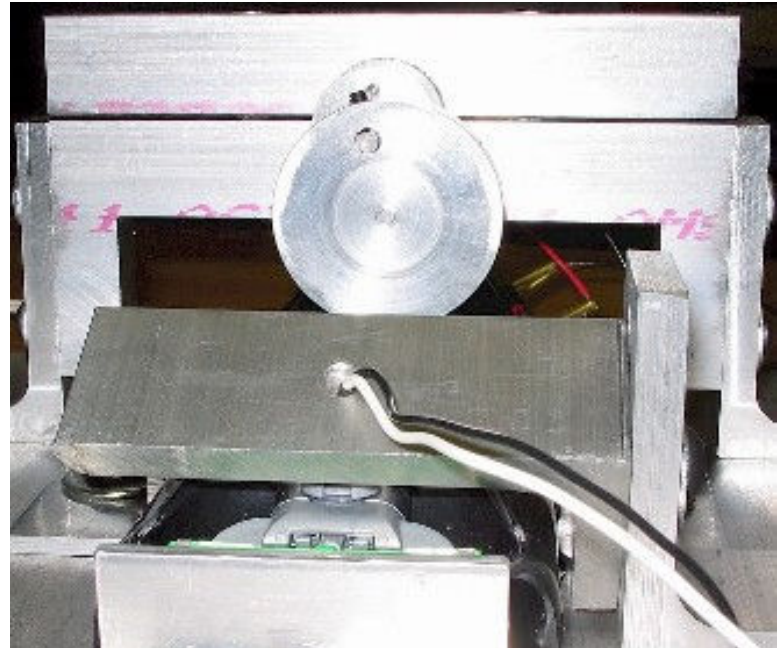

Figure 8 Front View of the Cam on the Button

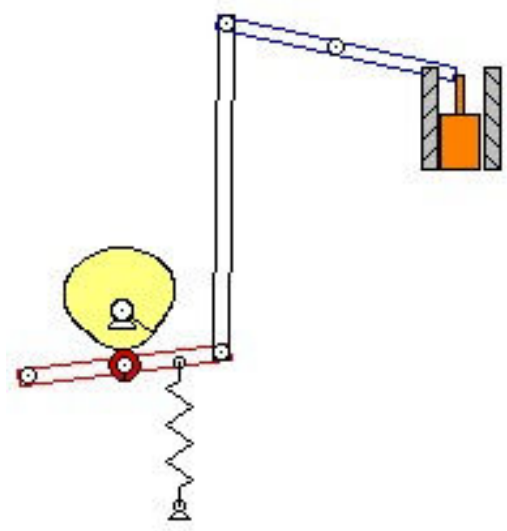

Figure 9 Simulation of a Cam 